\title{
PHYLLOTACTIC PATTERN FORMATION IN EARLY STAGES OF CACTUS ONTOGENY
}

\author{
EDYTA M. GOLA \\ Institute of Plant Biology, University of Wrocław \\ Kanonia 6/8, 50-328 Wrocław, Poland \\ e-mail: edytag@biol.uni.wroc.pl
}

(Received: February 27, 2006. Accepted: May 12, 2006)

\begin{abstract}
Representatives of the family Cactaceae are characterized by a wide range of phyllotaxis. To assess the origin of this diversity, early stages of phyllotactic pattern formation were examined in seedlings. The analysis of the sequence of areole initiation revealed intertribal differences. In seedlings from the Trichocereeae (Gymnocalycium, Rebutia) and Notocacteae (Parodia) tribes, two opposite cotyledonal areoles developed as the first elements of a pattern. Usually, next pair of areoles was initiated perpendicularly to cotyledonal areoles, starting the decussate pattern. This pattern was subsequently transformed into bijugate or into simple spiral phyllotaxis. In seedlings from the Cacteae tribe (Mammillaria and Thelocactus), cotyledonal areoles were never observed and the first areoles always appeared in the space between cotyledons. It was either areole pair (mainly in Mammillaria), starting a decussate pattern, or a single areole (mainly in Thelocactus) quickly followed by areoles spirally arranged, usually in accordance with the main Fibonacci phyllotaxis.

Differences in the initial stages of pattern formation do not fully explain the phyllotaxis diversity in mature cacti. Only two, the most common phyllotactic patterns occurred in the early development of studied seedlings, i.e. the main Fibonacci and the decussate pattern. Discrepancy in the range of phyllotactic spectra in seedlings and in mature plants suggests that phyllotaxis diversity emerges during further plant growth. Initial phyllotactic transformations, occurring already in the very early stages, indicate great plasticity of cactus growth and seem to support the hypothesis of the ontogenetic increase of phyllotaxis diversity due to transformations.
\end{abstract}

KEY WORDS: phyllotaxis, phyllotactic transformation, cactus ontogeny, Cactaceae.

\section{INTRODUCTION}

The evolutionary modification of morphogenetic processes, adapting cacti to diversified and often severe environments, has lead to emergence of the variety of morphological forms in the family Cactaceae (Barthlott and Hunt 1993; Anderson 2001; Wallace and Gibson 2002; Mauseth 2004). Within Cactaceae, there are shrubs and gigantic candelabra-like trees, cylindrical or globular plants growing alone or in compact clusters, flattened stems and tiny rosettes (e.g., Anderson 2001). Likely, this variety of morphological forms may facilitate diverse distribution of leaves, and thus, formation of different phyllotactic patterns. The phenomenon of phyllotaxis refers to regular patterning of lateral organs in a shoot, e.g. areoles (=modified axillary buds or shoots; Boke 1953, 1961; Freeman 1970) in case of cacti. Areoles, ontogenetically related to developing leaves (Boke 1953, 1954, 1961; Mauseth 1980, 2004; Gibson and Nobel 1986; Salgado Terrazas and Mauseth 2002), reflect positions of vestigial leaves and can be considered as elements of a phyllotactic pattern. In most of cacti with spiral phyllotaxis, areoles are conspicuously and regularly arranged and can be easily connected by spiral lines forming two oppositely winding sets. Numbers of such intersecting spirals represent subsequent elements of a phyllotactic series in which every element is the sum of two preceding numbers. Two consecutive members of a phyllotactic series, corresponding to the number of spirals being in a contact at the stem surface, are called a contact parastichy pair (Church 1904). The pair identifies unequivocally the phyllotactic series to which it belongs and a pattern expression. It also defines indirectly the configuration of the ontogenetic spiral when orientation of opposite parastichies is determined (Zagórska-Marek 1994). The most common patterns are identified by contact parastichy pairs belonging to the main Fibonacci series: 1, 2, 3, 5, 8, 13, $21, \ldots$ Other spiral patterns are mostly occasional in seed plants (e.g., Schwabe 1984; Zagórska-Marek 1985, 1987, 1994).

Despite quite intensive studies on cactus specific morphological features (e.g., Boke 1953, 1954, 1957, 1961; Mauseth 1978a, b, 1980, 2004), there is no detailed survey 
or systematic screening of phyllotactic patterns. Nevertheless, information available in literature, although scarce, suggests an existence of pattern diversity within the family Cactaceae related indirectly to taxonomic position of an investigated plant. For instance, in leaf-bearing shrubs representing the primitive subfamily Pereskioideae (Boke 1954; Bailey 1960; Gibson 1976), as well as morphologically diverse cacti from the subfamily Opuntioideae (Bailey 1964; Freeman 1970; Gibson 1976; Gibson and Nobel 1986), the most common phyllotactic pattern - the main Fibonacci is reported. Surprisingly, this pattern is frequently maintained during formation of flat cladodes in opuntias (Gibson 1976; Gibson and Nobel 1986) despite changes of the shoot symmetry. Within the more succulent subfamily Cactoideae, distichy characterizes majority of flattened stems, especially in genus Epiphyllum (the Hylocereee tribe; Rauh 1979) whereas spiral phyllotaxes, conspicuous due to a dense areole packing and a limited internodal growth (Gibson and Nobel 1986), are typical for globular and cylindrical cacti. Among these, the short columnar Echinopsis representing the tribe Trichocereeae was possibly the first genus for which few unusual phyllotactic patterns were reported (Church 1904). Church, in his classical work on phyllotaxis (1904), showed the extensive range of patterns in Echinopsis, comprising of either true whorls or typical spiral patterns with much the same numbers in a contact parastichy pair, e.g. 6:6, 6:7, 6:8, etc. Cactus adaptation to harsh environmental conditions was a suggested reason for occurrence of such patterns (Church 1904). Rebutia, another genus from the Trichocereeae tribe, shares phyllotaxis variety with Echinopsis. The broad spectrum of various phyllotactic patterns, including many infrequent accessory ones, is characteristic of Rebutia. Patterns other than the main Fibonacci often co-dominate or even prevail in this genus (Gola 1997). For Mammillaria, belonging to the tribe Cacteae, spiral areole arrangements are so conspicuous that the numbers of connecting spirals (= parastichies) have frequently been given in plant descriptions (Britton and Rose 1923; Craig 1945; Krainz 1956-75; Backeberg 1961; Rauh 1979). Comparing with the extensive pattern range in the similar in form tribe Trichocereeae, it can be quite surprising that, in Mammillaria, again the main Fibonacci is almost exclusively occurring pattern. Even the ontogenetic changes in this genus alter the pattern expression only (Gola 1997). Still, observations of the changeable numbers of ribs in Ferocactus and few genera belonging to this group (Gibson and Nobel 1986) as well as the numbers of parastichies in one set in few other genera (Mauseth 2004), suggest the presence of various phyllotactic patterns also in the tribe Cacteae.

Various phyllotaxes, occurring both in completely different morphologically plants as well as in similar specimens, pose the question about sources, time and modes of the diversity origin in Cactaceae. The main purpose of this research was to find out whether the pattern diversity is rooted in the initiation of the first areoles in a seedling or develops later, during further plant growth. What are the probable mechanisms involved in pattern diversification? Do any differences occur within the family, already in initial stages of pattern formation? The problem is more challenging as the opposite arrangement of cotyledons in seedlings is an initial condition for all these patterns so varied and variable in mature specimens.

\section{MATERIALS AND METHODS}

Genera representing different tribes of the subfamily Cactoideae (Cactaceae) were selected to compare the initial stages of phyllotactic pattern formation. Their choice was based on differences in phyllotaxis occurring in mature plants. This is why genera Mammillaria and Rebutia were analyzed in a first place - their phyllotactic patterns were previously screened (Gola 1997). The choice of other cactus species was partly limited by the seed availability. Seeds were obtained from the cactus collection of the Botanical Garden of University of Wrocław and from the private collection of Ms. Zofia Pyjek.

Regarding the most recent changes in classification and nomenclature within the family Cactaceae, a majority of cactus names is given according to the International Organization for Succulent Plant Study (IOS) checklist (Hunt 1992; Anderson 2001). Synonyms of chosen species are available at the website: www.cites.org. In few cases, obtained Mammillaria seeds belonged to taxa which species names were not accepted or only provisionally accepted by the IOS. Such species are marked in the list by an asterisk. Higher units, such as tribes and subfamilies, are distinguished based on the classification of Barthlott and Hunt (1993) recently supported by molecular data (Wallace and Gibson 2002).

Below is given the complete list of cactus species used during the study. Letters in square brackets show the source of seeds: the Botanical Garden of University of Wrocław [BG] or Ms. Z. Pyjek's collection [ZP]. An asterisk before Mammillaria species name indicates not known/not accepted by the IOS position of the taxon.

\section{Tribe Trichocereeae:}

Gymnocalycium bodenbenderianum (Hoss. ex Berg.) Hill [BG]; G. knebelii Frič [BG] - at present it is a doubtful species; G. ochoterenae Backeb.[BG]; Rebutia deminuta (Weber) Br. \& R. [BG]; R. fiebrigii (Gürke) Br. \& R. ex Bailey [BG]; R. pseudodeminuta Backeb. [BG].

\section{Tribe Notocacteae:}

Notocactus eugeniae Vliet [BG] - provisionally accepted species name in Hunt (1992), although the entire genus is currently included into Parodia (Hunt 1992, Anderson 2001); Parodia ottonis (Lehm.) Taylor [ZP].

\section{Tribe Cacteae:}

*Mammillaria flavovirens Salm-Dyck [ZP]; *M. fuscata var. sulphurea (Sencke) Backeb. [BG]; *M. kunzeana Böd. \& Quehl [BG]; M. morganiana Tieg. [BG]; *M. pyrrhocephala Scheidw. [BG]; M. schiedeana Ehrenb. [BG]; $M$. sempervivi DC. $[\mathrm{ZP}]$ and Thelocactus setispinus (Engelmann) Anderson [ZP].

Cactus seeds were removed from the fruit, cleaned out from remnants of a fruit tissue and rinsed few times in distilled water. Then, they were placed on the moist filter paper in closed Petri dishes and kept in room temperature (ca. $22^{\circ} \mathrm{C}$ ) until germination. Afterwards seedlings were planted into pots containing sterilized mixture of sand (ca. $50 \%$ ), leaf soil (ca. 30\%) and peat soil (ca. 20\%).

The sequence of areole initiation was followed in seedlings of studied species, starting from the cotyledonal stage. The emergence of the first areole(s) and successive developmental events were recorded using the Video-loupe 
Scalar VMS70 or the DXC-950P/Sony video-camera collaborating with the Stereo Microscope Olympus SZX-9. Macroscopic images of seedlings were directly sent into the graphic station Indy (Silicon Graphics). Based on sequential computer pictures, a general organography was established for each seedling and a phyllotactic pattern was identified using the formula of the contact parastichy pair (Church 1904; Zagórska-Marek 1985, 1987, 1994). The indexes $\mathrm{S}$ and $\mathrm{Z}$ in this formula indicate the orientation of parastichies with ascending clockwise parastichies described as $\mathrm{S}$ and counterclockwise as $\mathrm{Z}$.

To confirm the occurrence of a particular pattern, divergence angles were measured. The special computer program Phyll. 2.0 was used to determine the apex geometric center for each seedling prior to the measurement and to calculate divergence angles (Matkowski et al. 1998).

\section{RESULTS}

\section{Frequency of phyllotactic patterns}

Initial areole arrangements, observed in studied seedlings, started formation of few the most common phyllotactic patterns (Table 1). The prevalence of a particular pattern was associated with the taxonomic position of genus. In cactus seedlings from the tribe Trichocereeae, the decussate pattern prevailed (ca. 50\% of all patterns) in early developmental stages; the main bijugy and Fibonacci patterns were less frequent (ca. 15-20\%). Other patterns, including Lucas and tricussate phyllotaxis, occurred with frequency below $10 \%$ (Table 1). In the tribe Notocacteae, the main
Fibonacci and decussate patterns co-dominated, having each ca. $30 \%$ occurrences. In the tribe Cacteae, the main Fibonacci pattern apparently prevailed (Table 1).

\section{The initial pattern formation}

and ontogenetic transformations

The position and the number of firstly appearing areoles as well as the type and frequency of changes in their further spacing, showed intergeneric and intertribal differences (Tables 1, 2, Fig. 1).

\section{Trichocereeae: Gymnocalycium and Rebutia. Notocacteae: Parodia and Notocactus}

The initial stages of pattern formation were basically similar in seedlings representing both of these separate tribes, therefore in this paper genera belonging either to the Notocacteae or to the Trichocereeae are considered together.

The first step of pattern formation was the initiation of the pair of cotyledonal areoles. The areoles developed in cotyledonal axils, marking precisely the circumferential position of cotyledons (Figs 2A, B, D, E). In rare case of tricotyly (Gymnocalycium and Parodia seedlings, Table 1), the number of cotyledonal areoles increased to three along with the increase of cotyledons (Fig. 2C). The subsequent pattern could be formed in few different ways (Table 2). In most of the seedlings, successively appearing areoles were still initiated in whorls of two or three depending upon the initial number of cotyledons. Areoles of the consecutive whorl were positioned exactly in the middle of the circumferential distance between the areoles of the previous whorl, forming the regular decussate or tricussate pattern,

TABLE 1. Initial areole arrangements in cacti. Patterns identified in examined seedlings are presented as the number of all occurrences for each species and as a percentage for a genus. In seedlings undergoing phyllotactic transformations (changing the initial pattern), an areole arrangement before the change and a resultant pattern were counted as independent cases. A single pair of areoles as well as two pairs arranged in the decussate manner occurred only at the beginning of pattern formation. Seedling development could have been temporarily stopped at this stage (e.g. in Gymnocalycium, Notocactus) or initial pattern transformed into a new quality.

\begin{tabular}{|c|c|c|c|c|c|c|c|c|}
\hline \multirow{2}{*}{$\stackrel{8}{:}$} & \multirow{2}{*}{ Species } & \multicolumn{7}{|c|}{ Initial areole arrangement (initial phyllotaxis) } \\
\hline & & One pair & Decussate & Tricussate & Main bijugy & Fibonacci & Lucas & Other patterns \\
\hline \multirow{8}{*}{ 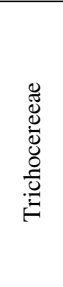 } & Gymnocalycium bodenbenderianum & 3 & 20 & 2 & 4 & 9 & 2 & - \\
\hline & G. knebellii & 1 & 7 & 2 & 1 & 2 & - & - \\
\hline & G. ochotereneae & 1 & 8 & 3 & 4 & 4 & - & $1 \times$ whorled $3: 3$ \\
\hline & Total for Gymnocalycium & $6.7 \%$ & $47.3 \%$ & $9.5 \%$ & $12.2 \%$ & $20.3 \%$ & $2.6 \%$ & $1.4 \%$ \\
\hline & Rebutia deminuta & - & 15 & - & 6 & 6 & - & - \\
\hline & R. fiebrigii & - & 68 & - & 37 & 24 & 4 & $1 \times 4: 5$ \\
\hline & R.pseudodeminuta & 1 & 51 & - & 24 & 14 & 10 & $5 \times 4: 5$ \\
\hline & Total for Rebutia & $0.4 \%$ & $50.5 \%$ & - & $25.3 \%$ & $16.6 \%$ & $5.3 \%$ & $1.9 \%$ \\
\hline \multirow{3}{*}{ 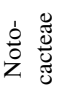 } & Notocactus eugeniae & 2 & 6 & - & 3 & 1 & - & - \\
\hline & Parodia ottonis & 15 & 23 & 2 & 5 & 26 & 3 & - \\
\hline & Total for Parodia & $19.8 \%$ & $33.7 \%$ & $2.3 \%$ & $9.3 \%$ & $31.4 \%$ & $3.5 \%$ & - \\
\hline \multirow{10}{*}{ U. } & Mammillaria flavovirens & 63 & 6 & - & - & 70 & - & - \\
\hline & M. fuscata & 16 & 8 & - & 3 & 29 & - & - \\
\hline & M. kunzeana & 16 & 7 & - & 3 & 20 & - & - \\
\hline & M. morganiana & 5 & 5 & - & 1 & 8 & - & - \\
\hline & M. pyrrhocephala & 16 & 4 & - & 3 & 14 & - & - \\
\hline & M. schiedeana & 6 & 3 & - & 1 & 8 & - & - \\
\hline & M. sempervivi & 6 & - & - & - & 6 & - & - \\
\hline & Total for Mammillaria & $39.1 \%$ & $10.1 \%$ & - & $3.4 \%$ & $47.4 \%$ & - & - \\
\hline & Thelocactus setispinus & 17 & - & - & - & 48 & - & - \\
\hline & Total for Thelocactus & $26.2 \%$ & - & - & - & $73.8 \%$ & - & - \\
\hline
\end{tabular}


TABLE 2. Transformations of the initial pattern. Qualitative transformations of the initial pattern in studied seedlings referred mainly to changes from paired to spiral areole arrangements. The frequency of transformations is given as a total number and a percentage of all seedlings undergoing a particular transformation. In few cases (Rebutia), the qualitative transformation occurred twice in the same seedling, changing phyllotaxis from decussate to bijugate and, next, to a simple spiral pattern: Fibonacci, Lucas or $4: 5$ pattern, representing the $1,4,5,9, \ldots$ series.

\begin{tabular}{|c|c|c|c|c|c|c|}
\hline \multirow{2}{*}{$\stackrel{8}{\mathscr{B}}$} & \multirow[b]{2}{*}{ Species } & \multicolumn{5}{|c|}{ Transformation of the initial pattern } \\
\hline & & $\begin{array}{c}\text { One pair } \\
\text { to simple spiral }\end{array}$ & $\begin{array}{c}\text { Decussate } \\
\text { to simple spiral }\end{array}$ & $\begin{array}{c}\text { Decussate } \\
\text { to main bijugy }\end{array}$ & Other & $\begin{array}{c}\text { Number } \\
\text { of seedlings }\end{array}$ \\
\hline \multirow{8}{*}{ 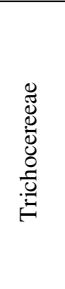 } & Gymnocalycium bodenbenderianum & 3 & 8 & 4 & - & 25 \\
\hline & G. knebellii & 1 & 1 & 1 & - & 10 \\
\hline & G. ochotereneae & 1 & 3 & 4 & - & 13 \\
\hline & Total for Gymnocalycium & $10.4 \%$ & $25.0 \%$ & $18.8 \%$ & - & 48 \\
\hline & Rebutia deminuta & - & 6 & 6 & - & 15 \\
\hline & R. fiebrigii & - & 26 & 37 & $3 \times$ bijugy to simple spiral & 68 \\
\hline & R. pseudodeminuta & 1 & 23 & 24 & $5 \times$ bijugy to simple spiral & 51 \\
\hline & Total for Rebutia & $0.7 \%$ & $41.0 \%$ & $50.1 \%$ & $6.0 \%$ & 134 \\
\hline \multirow{3}{*}{ 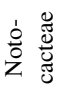 } & Notocactus eugeniae & - & 1 & 3 & - & 8 \\
\hline & Parodia ottonis & 12 & 17 & 5 & $1 \times$ decussate to tricussate & 42 \\
\hline & Total for Parodia & $24.0 \%$ & $36.0 \%$ & $16.0 \%$ & $2.0 \%$ & 50 \\
\hline \multirow{10}{*}{ 离 } & Mammillaria flavovirens & 63 & 6 & - & - & 70 \\
\hline & M. fuscata & 16 & 5 & 3 & - & 32 \\
\hline & M. kunzeana & 16 & 4 & 3 & - & 26 \\
\hline & M. morganiana & 4 & 4 & 1 & - & 9 \\
\hline & M. pyrrhocephala & 14 & - & 3 & - & 20 \\
\hline & M. schiedeana & 6 & 2 & 1 & - & 10 \\
\hline & M. sempervivi & 6 & - & - & - & 6 \\
\hline & Total for Mammillaria & $72.3 \%$ & $12.1 \%$ & $6.4 \%$ & - & 173 \\
\hline & Thelocactus setispinus & 17 & - & - & - & 48 \\
\hline & Total for Thelocactus & $26.2 \%$ & - & - & - & 48 \\
\hline
\end{tabular}

respectively (Figs 2A, C, Tables 1,3). Because of the low growth rate in some Gymnocalycium and Parodia seedlings, one pair of cotyledonal areoles or two areole pairs arranged in the decussate manner were occasionally the only observed patterns in the course of the studies (Table 1).

In faster growing species, the initial decussate pattern was frequently changed due to circumferential displacement of areole pairs, starting from the third one (Figs 2D-F). They were shifted by less than a half of circumferential distance between areoles of the former pair (less than $90^{\circ}$ ), gradually changing position of emerging pairs from $90^{\circ}$ to approximately $70^{\circ}$. As a result, the main bijugate pattern developed, initially in the expression 2:4 (Tables 2, 3; Figs 2D-E). Later, the number of contact parastichies quickly increased within the same series (=a change of pattern expression) to the expression 4:6 (Fig. 2F). This initial transformation from the decussate pattern to the main bijugy was typical of Rebutia (ca. 50\% plants; Table 2). It also occurred in other genera from both tribes, although in fewer seedlings (ca. 15-18\%; Table 2).

In some seedlings of Rebutia, approximately one year old, in which the main bijugate pattern in expression 4:6 was previously observed, next transformation took place changing phyllotaxis into a simple spiral pattern expressed by $4: 5$ contact parastichies representing series $1,4,5,9$, $14, \ldots$ (Tables 1, 2; Fig. 3A).

In all studied genera from these tribes, the initial paired arrangement of areoles could change directly into a simple spiral pattern (Table 2). It happened either after the initiation of the cotyledonal areole pair (mainly Parodia, ca. 25\% seedlings, Table 2; Fig. 2I) or after development of two decussate pairs (all genera, ca. 25-40\%, Table 2; Figs 2G, H). Successive single areoles began to appear separately, in a spiral sequence, usually forming low expressions of the main Fibonacci pattern (1:2 or $2: 3$ contact parastichy pairs). This pattern frequently continued during the further seedling growth,

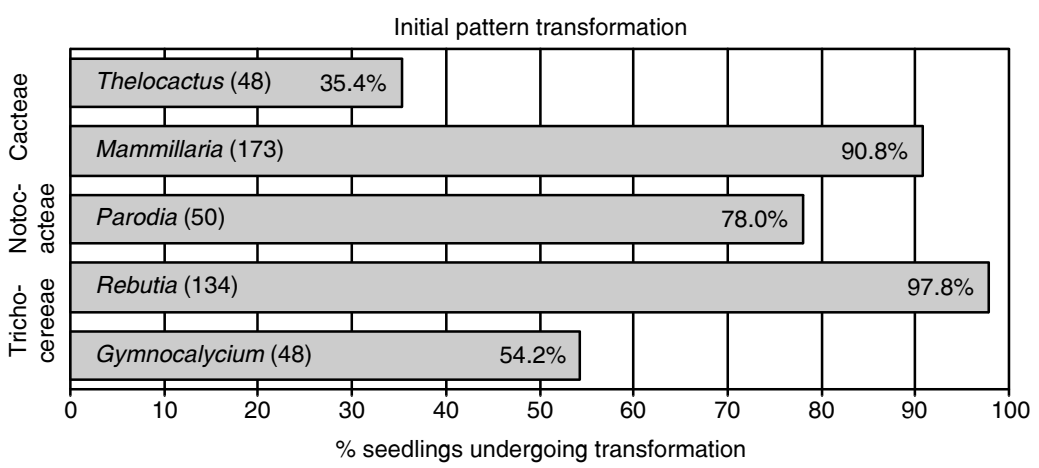

Fig. 1. Frequency of qualitative transformations in cactus seedlings. The number of examined specimens from each genus is given in the brackets. In all studied plants, initial areole arrangement ontogenetically changed into a different pattern. Almost all one year old Mammillaria and Rebutia seedlings underwent transformation whereas in Thelocactus seedlings in the same age the initial pattern changed less frequently. 

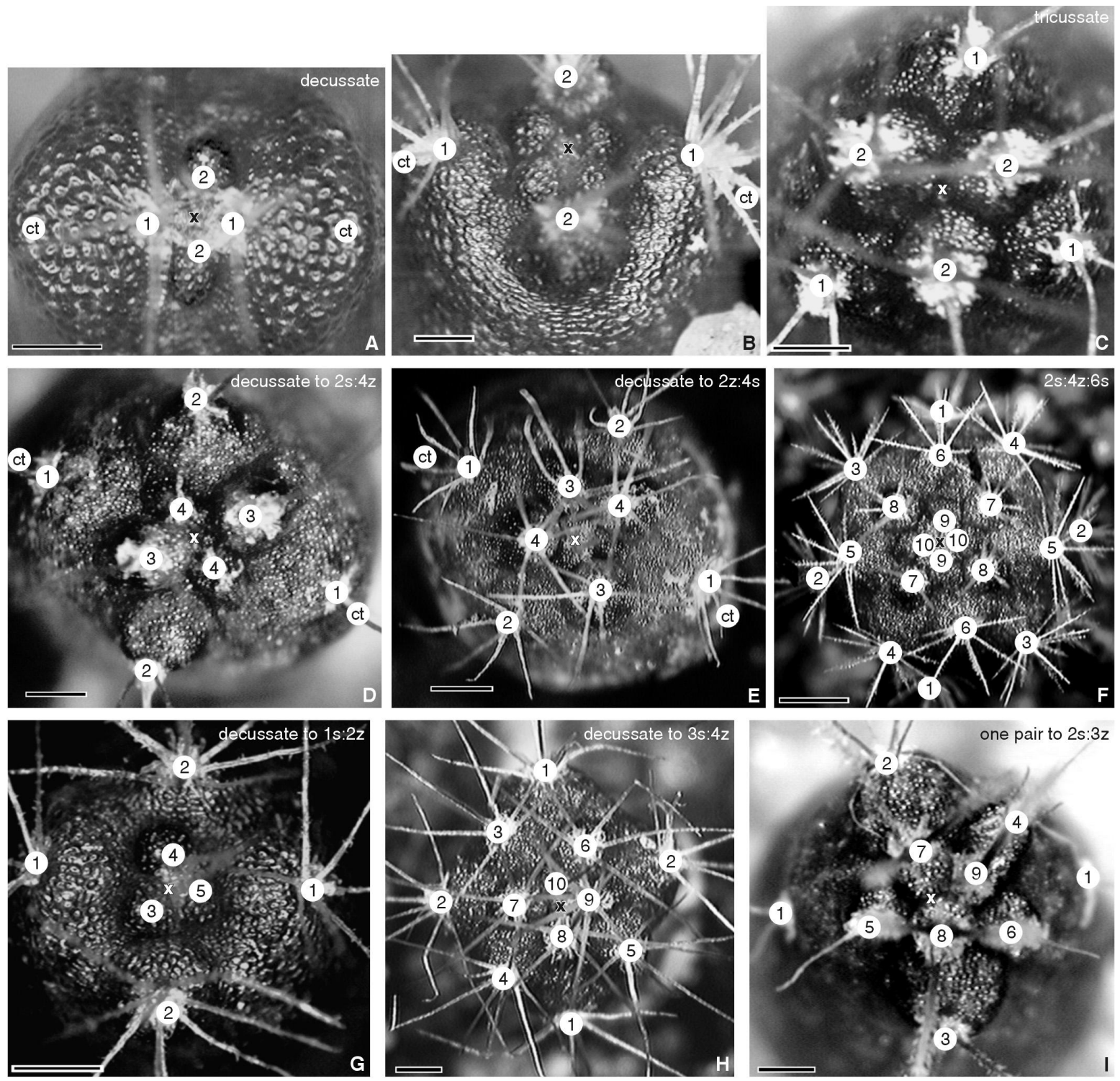

Fig. 2. The sequence of areole emergence in studied cacti. In all images, successive numbers $(1,2,3, \ldots)$ refer to the order of initiation with the oldest, developed as first an areole or areole pair having the lowest number and the youngest one described by the highest number. $\mathrm{S}$ and $\mathrm{Z}$ in the formula of the contact parastichy pair indicate the orientation of opposed sets of parastichies: ascending clockwise (S) and counterclockwise (Z).

A - top view of Rebutia pseudodeminuta seedling. The pair of cotyledonal areoles (1) is located in axils of reduced cotyledons (ct) marking their circumferential position. The second pair of areoles (2), which primordia are already visible at the apex, is initiated perpendicularly to the first pair, starting decussate pattern. B - half-profile of Rebutia fiebrigii seedling presenting cotyledonal areoles (1) developing directly above cotyledons (ct) and the second, perpendicular pair of areoles (2). $\mathbf{C}$ - top view of tricotyledonous seedling of Gymnocalycium bodenbenderianum. Parallel to the increase of the cotyledon number, three cotyledonal areoles appear (1). Successive areoles are initiated in a whorl of three, in the middle of the distance between cotyledonal areoles. The maintenance of such areole spacing causes emergence of regular tricussate phyllotaxis. D-F - ontogenetic transformation from the initial decussate pattern to the main bijugy. The first and the second areole pairs are arranged according to the decussate pattern. The third pair is slightly shifted from the right angle typical of the decussate pattern starting transformation to a new pattern - the main bijugy. D - Gymnocalycium bodenbenderianum and $\mathbf{E}-$ Parodia ottonis. Reduced cotyledons (ct) are still discernible below cotyledonal areoles (1); F - the older seedling of Rebutia fiebrigii with the main bijugy expressed by the $2 \mathrm{~s}: 4 \mathrm{z}$ contact parastichy pair, which appeared after transformation from the initial decussate arrangement. The set of the sixth S-oriented parastichies is also present. Initial decussate pair is, however, much below visible upper part of the seedling and is not numbered. G-I - ontogenetic transformation to a simple spiral pattern in Rebutia deminuta $(\mathbf{G})$, Parodia ottonis $(\mathbf{H})$ and Gymnocalycium bodenbenderianum $(\mathbf{I})$. After initiation of either two decussate pairs $(\mathbf{G}, \mathbf{H})$ or only one pair $(\mathbf{I})$, initial areole arrangement changes forming a simple spiral pattern. New primordia start appearing separately in a spiral sequence, usually according to the main Fibonacci pattern ( $\mathbf{G}$ and $\mathbf{I})$ but other simple spiral patterns can also be formed, e.g. the Lucas pattern (H).

Abbreviations: $\mathrm{ct}-$ cotyledon; $\mathrm{x}-$ indicates position of the apex. $\mathrm{Bar}=1 \mathrm{~mm}$.

usually in a higher expression (e.g., 3:5 or 5:8). In few cases, instead of the main Fibonacci, the Lucas pattern with the series $1,3,4,7, \ldots$ was formed (Table 1; Fig. $2 \mathrm{H}$ ).
Pattern formation in the tribe Trichocereeae and Notocacteae was dynamic: the initial areole arrangement changed in a majority of seedlings (Table 2; Fig. 1). Someti- 

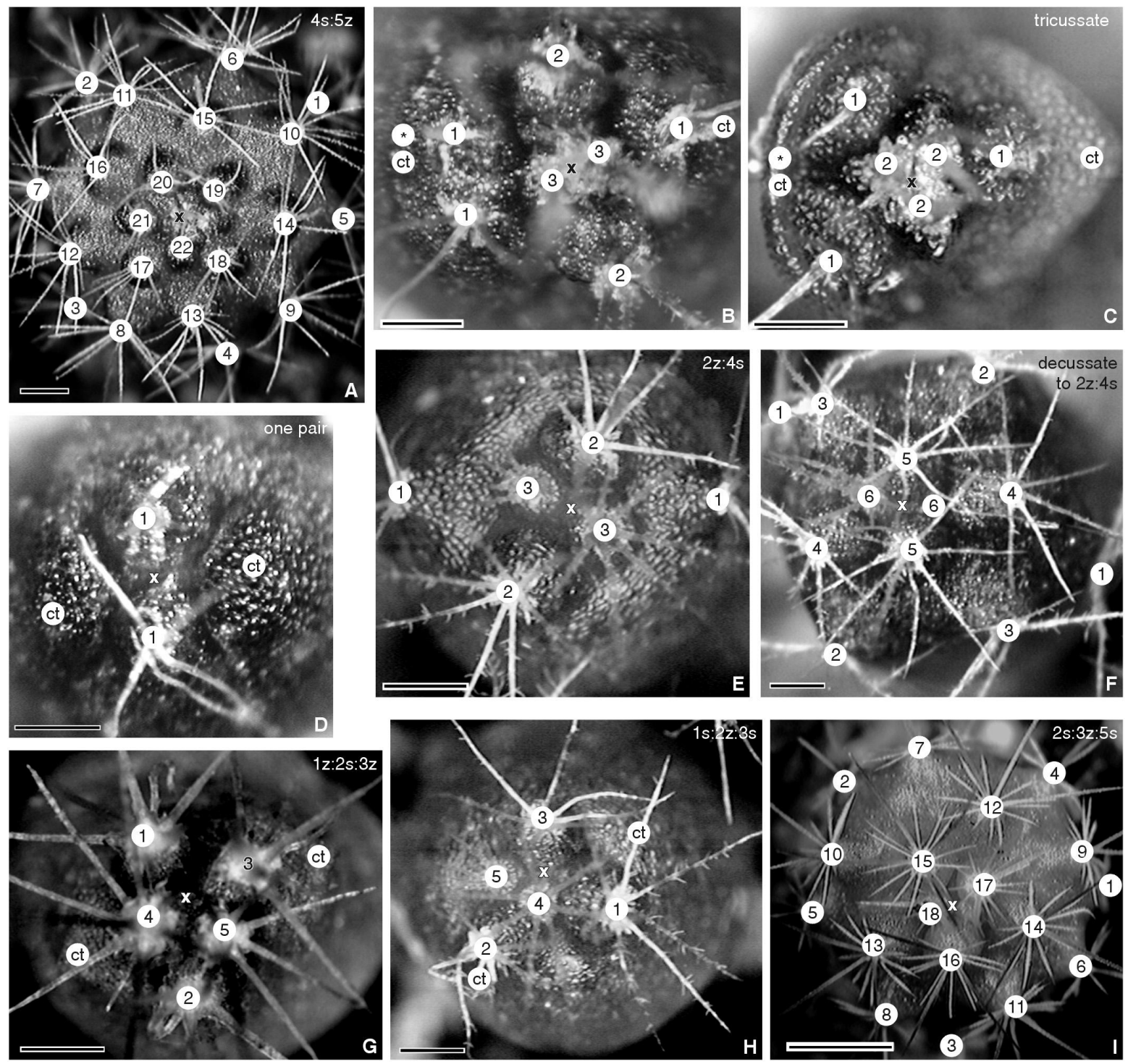

Fig. 3. Phyllotactic pattern formation in examined seedlings. Similarly to Figure 2, areoles are numbered according to the sequence of appearance: the oldest, first initiated areole or areole pair has the lowest number, next ones are labeled with successive numbers. S and $\mathrm{Z}$ in the formula of the contact parastichy pair indicate the orientation of opposed sets of parastichies: ascending clockwise (S) and counterclockwise (Z).

A - Rebutia pseudodeminuta seedling showing relatively rare phyllotactic pattern $4 \mathrm{~s}: 5 \mathrm{z}$ belonging to the series $1,4,5,9, \ldots$ Such a pattern was observed in few one-year old seedlings of Rebutia as a result of two consecutive ontogenetic transformations: from initially decussate pattern into the main bijugy and, then, to the 4:5 pattern. B, C - irregularities in Gymnocalycium development. In pictured seedlings cotyledons (ct) are uneven in size; the larger one is labeled with an asterisk $\left(^{*}\right)$. In the axil of the bigger cotyledon two areoles are initiated, while in the opposite side only one areole appears. This unusual initial arrangement can start formation of different phyllotactic patterns. B - G. bodenbenderianum - despite the atypical number and spacing of firstly initiated cotyledonal areoles, next areoles are initiated in whorls of two. The second and the third pair are slightly oblique to each other. C - G. knebelii - presence of three cotyledonal areoles results in regular tricussate pattern formation. D-F - initial areole arrangements in Mammillaria kunzeana (D), M. pyrrhocephala $(\mathbf{E})$ and $M$. fuscata var. sulphurea $(\mathbf{F})$. Pattern formation often starts from paired arrangement of the first two areoles (D) which always appear in the space between cotyledons (ct). Successive areoles can be initiated in pairs but their arrangement changes starting formation of the main bijugy (E, F). G-Thelocactus setispinus - firstly, one areole appears in the space between cotyledons (ct). Then, successive areoles are initiated separately, forming the low expression of the main Fibonacci pattern (1z:2s). H, I - top views of Mammillaria fuscata var. sulphurea seedlings producing the main Fibonacci phyllotaxis. From the beginning, areoles are initiated separately between cotyledons (ct) and the low expression, 1s:2z, of the main Fibonacci pattern is formed $(\mathbf{H})$. Together with expansion of the apex and initiation of successive areoles, the pattern expression changes to higher numbers of the contact parastichies, 3z:5s (I)

Abbreviations: $\mathrm{ct}-$ cotyledon; * - an asterisk indicating bigger cotyledon in the unevenly expanded pair; $\mathrm{x}-$ marks position of the apex. Bar $=1 \mathrm{~mm}$.

mes, as in case of Rebutia, even two transformations could occur in the same seedling (Fig. 3A).

Growth irregularities were observed in two Gymnocalycium seedlings where circumferential sectors, occupied by cotyledons, were uneven (Figs 3B, C). Above the bigger cotyledon two laterally adjacent cotyledonal areoles were initiated, whereas only one areole appeared above the smaller opposite cotyledon. In G. bodenbenderianum (Fig. 3B) 
TABLE 3. Values of divergence angles in studied species. Divergence angle for simple spiral patterns is given almost exclusively for different expressions of the main Fibonacci and, in case of Parodia ottonis, for the Lucas pattern. If the initial pattern was transformed, divergence angle was measured independently for the initial areole arrangement and for the resultant phyllotaxis. All measurements are given as the mean value \pm standard error.

\begin{tabular}{|c|c|c|c|c|c|}
\hline \multirow{2}{*}{$\stackrel{8}{:}$} & \multirow{2}{*}{ Species } & \multicolumn{4}{|c|}{ Divergence angle $\left({ }^{\circ}\right)$} \\
\hline & & Decussate pattern & Tricussate pattern & Main bijugy & Simple spiral pattern \\
\hline \multirow{6}{*}{ 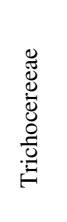 } & Gymnocalycium bodenbenderianum & $83.3 \pm 1.60$ & $61.9 \pm 1.88$ & $69.8 \pm 1.47$ & $131.1 \pm 2.56$ \\
\hline & G. knebelii & $89.9 \pm 1.51$ & $65.5 \pm 3.31$ & - & $122.2 \pm 2.70$ \\
\hline & G. ochoterenae & $90.6 \pm 1.14$ & $58.2 \pm 0.66$ & - & - \\
\hline & Rebutia deminuta & $90.9 \pm 0.56$ & - & $72.7 \pm 2.51$ & $136.6 \pm 2.71$ \\
\hline & R. fiebrigii & $90.5 \pm 0.61$ & - & $69.9 \pm 1.79$ & $137.2 \pm 1.80$ \\
\hline & R. pseudodeminuta & $88.3 \pm 1.72$ & - & $69.8 \pm 2.26$ & $138.0 \pm 2.48$ \\
\hline \multirow{2}{*}{ 方 } & Notocactus eugeniae & $89.8 \pm 0.58$ & - & - & $124.5 \pm 3.86$ \\
\hline & Parodia ottonis & $89.0 \pm 2.18$ & - & $72.4 \pm 4.44$ & $\begin{array}{c}137.4 \pm 3.01 \\
99.5 \pm 1.79 \text { Lucas }\end{array}$ \\
\hline \multirow{8}{*}{ 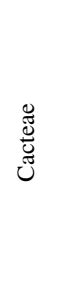 } & Mammillaria flavovirens & $88.1 \pm 2.86$ & - & - & $137.4 \pm 0.71$ \\
\hline & M. fuscata & - & - & - & $136.7 \pm 1.85$ \\
\hline & M. kunzeana & - & - & - & $136.4 \pm 1.48$ \\
\hline & M. morganiana & $90.4 \pm 1.72$ & - & - & $133.1 \pm 1.85$ \\
\hline & M. pyrrhocephala & - & - & - & $137.3 \pm 1.60$ \\
\hline & M. schiedeana & $89.6 \pm 3.80$ & - & - & $133.7 \pm 2.06$ \\
\hline & M. sempervivi & - & - & - & $136.5 \pm 1.36$ \\
\hline & Thelocactus setispinus & $89.6 \pm 0.79$ & - & - & $136.1 \pm 1.32$ \\
\hline
\end{tabular}

despite the unusual number and circumferential position of cotyledonal areoles, next areoles were arranged in slightly oblique pairs, starting either decussate or bijugate pattern. In the second case, G. knebelii (Fig. 3C), the unusual initial areole arrangement led ultimately to the regular tricussate pattern.

\section{Cacteae: Thelocactus and Mammillaria}

Both genera, Thelocactus and Mammillaria, followed similar and more uniform rules of pattern formation than cacti from the previous group (Tables 1, 2; Figs 3D-I). Development of cotyledonal areoles was never observed in any of the examined seedlings from this tribe, and the first areole(s) always appeared in the space between cotyledons (Figs 3D, G, H). Phyllotactic pattern formation started usually from paired arrangement of the first two areoles. Initiation of next, already single areole showed a transition to a simple spiral pattern. This way of pattern formation was the most frequent for Mammillaria and occurred in more than $70 \%$ of all seedlings (Table 2). Rarely, areoles remained initiated in pairs, gradually forming the main bijugate pattern (Tables 1, 2; Figs 3E, F).

Alternatively, pattern formation started directly from the first and a single areole followed by others spirally initiated, according to the main Fibonacci pattern (ca. 20\% Mammillaria and ca. 65\% Thelocactus seedlings). At the beginning, low expressions of this pattern were formed: 1:2 and 2:3 (Figs 3G, H). The increase in contact parastichy numbers to higher expression (3:5) took place during subsequent growth of a seedling (Fig. 3I).

\section{DISCUSSION}

Early stages of phyllotactic pattern formation in cacti demonstrate that the initial areole arrangements show low di- versity with almost exclusively the main Fibonacci, bijugate and decussate patterns. Such results are not surprising as low expressions of these patterns are the most probable arrangements developing through transition from a pair of cotyledons (Zagórska-Marek 1987) or from opposite prophylls in lateral branches (Zagórska-Marek, unpublished). This is also why they are the most common patterns in flowering plants (e.g., Schwabe 1984; Zagórska-Marek 1994). The remarkable discrepancy between limited initial phyllotaxis and a pattern variety in mature cacti, as e.g. in Rebutia (Gola 1997), suggests that diversity arises not at the very beginning of pattern formation but during later stages of seedling growth. It can be hypothesized that phyllotaxis diversity in cacti arises due to the ontogenetic changes of the initial pattern. High frequency of ontogenetic transformations, occurring in the initial developmental stages and in young plants, may support this hypothesis.

Different types of transformations occurred in the examined seedlings that changed either the way of pattern expression within the same series or the type of phyllotactic series, i.e. a quality of a pattern. Regardless the resultant phyllotaxis, they appear to be a response to developmental changes of an areole primordium size relative to the expanding apex surface. The rapid and considerable increase of a shoot apical meristem (SAM) dimension, typical of the early stages of cactus ontogeny (Mauseth 1978a, b, 2004), probably promotes transformations. Despite the promptness of the surface expansion, proportions of particular SAM zones remain constant (Mauseth and Niklas 1979; Mauseth 2004). A relative decrease of primordium size compared to the quickly growing apex (Mauseth 2004) causes more compact packing of primordia. In Mammillaria, Thelocactus and in bijugate Rebutia seedlings, such changes of SAM proportions resulted mainly in quantitative transformations, i.e. in a change of contact parastichy numbers within the same phyllotactic series. Similar onto- 
genetic changes of the main Fibonacci expression were also characteristic of mature Mammillaria specimens (Gola 1997). Balanced and continuous modifications of SAM growth parameters in a developing plant were previously postulated to be a main mechanism of phyllotactic transformation in which only pattern expression changed (Zagórska-Marek 1987, 1994). In addition, computer modeling of pattern formation in capitula of the Asteraceae demonstrated presence of such quantitative transformations due to accumulation of minute but steady changes in the apex (Douady and Couder 1996). Uniform developmental alterations of the apex proportions in cactus seedlings, exemplified by a quick increase of initial parastichy numbers within one phyllotactic series, seem to be consistent with this conceptual mechanism.

The different type of transformation that changes a pattern quality from initially decussate into a bijugate (as e.g. in Rebutia) or into a simple spiral phyllotaxis is evident due to the angular areole displacement regarding their expected position based on arrangement of the existing primordia.

In Rebutia seedlings, areoles remain initiated in whorls of two but their spatial arrangement alters into the main bijugy. It means that, in reiterations, position of subsequent areole pair differs from the expected right angle typical of the decussate pattern, reaching gradually approximately $70^{\circ}$ between pairs. As recent studies on phyllotaxis have demonstrated, the primordium position is dependent on and regulated by auxin distribution within the SAM (Reinhardt et al. 2000, 2003; Kuhlemeier and Reinhardt 2001; Stieger et al. 2002; Jönsson et al. 2006). SAM regions with locally elevated auxin concentration are predestined to initiate a new primordium. Auxin is thought to be transported acropetally to the site of initiation of new primordium in the cells of the L1 layer. New primordium acts as auxin sink for surrounding cells, causing depletion of auxin in the neighborhood and inhibiting formation of next primordium in this site. Nearby to the region of auxin depletion, auxin concentration increases again due to its acropetal transportation in the L1, inducing initiation of next primordium (Reinhardt et al. 2000, 2003; Kuhlemeier and Reinhardt 2001; Stieger et al. 2002; Jönsson et al. 2006). According to this auxin model, the most probable site for initiation of the third areole pair in Rebutia is above cotyledonal areoles that would result in maintenance of the decussate pattern. However, in Rebutia, the third pair is angularly shifted starting transition to the main bijugy. It may be hypothesized that, in these seedlings, the site above cotyledonal areoles (expected place for the third pair) is depleted of auxin due to reinforcement of auxin sinking by these areoles because of their closeness to cotyledons. Cotyledons may also cause auxin depletion in nearby tissues. Alternatively, this transformation may be explained by the inhibiting effect of high concentration of auxin on organogenesis (e.g., Reinhardt et al. 2000). Hypothetically, superimposed vascular traces to cotyledons and to their areoles may be a source of high local concentration of auxin, since its acropetal transport via vascular elements has been postulated to be an alternative way of long distance auxin transportation within the apex (Banasiak 2005; Aloni et al. 2006).

Likely, a similar mechanism is involved in formation of the main trijugy. In tricotyledonous seedlings, e.g. in Gym- nocalycium, the regular tricussate pattern is usually formed and, possibly, it may transform into the trijugate pattern. The main trijugy was not currently observed in seedlings, although it was a quite frequent pattern in some of previously examined mature specimens of Rebutia (Gola 1997).

Formation of a simple spiral phyllotaxis due to transformation is considered to be a typical developmental process in early morphogenesis of dicotyledonous plants (Schwabe 1984; Lyndon 1998). This type of transformation requires the alteration of the initial shoot symmetry (Douady and Couder 1998; Hudson 2000) and changes the number of simultaneously initiated elements at the apex. Developmental establishment of a shoot axis in a seedling may be the consequence of the embryo polarity and development (Hudson 2000). Opuntia embryos, for example, have cotyledons distinctly uneven in size (Freeman 1970; Gibson 1976) what may introduce the initial asymmetry and may play role in spiral pattern formation. For other cactus genera with strongly reduced cotyledons (Mauseth 1978b, 2004) the mechanism of a symmetry break has to be different. According to one hypothesis, emergence of local discontinuous changes of circumference in the growing apex may be a mechanism responsible for qualitative transformations (Zagórska-Marek 1987, 1994). The presence of local disproportions at the shoot can be exemplified by fusion and split of ribs in rib-forming mature cacti (e.g. in Echinocactus; Boke 1957) or by unevenness of sectors occupied by cotyledons (e.g., Gymnocalycium seedlings). In this theory, local enlargement or decrease of the apex circumference may break the previous symmetry and trigger transformation of a previous pattern to a new quality (Zagórska-Marek 1987, 1994). A rarity of such big sectorial changes in cactus seedlings and relatively balanced growth of their apices (Mauseth and Niklas 1979) may imply, however, that such a mechanism of transformation is not widespread in early stages of cactus ontogeny but it may be more common in mature specimens.

Cactus seedlings are able to undergo phyllotactic transformations. These ontogenetic changes of the initial pattern increase the range of phyllotactic spectrum observed in mature plants. It has not been elucidated, however, why in some genera the pattern is quickly stabilized (as in Mammillaria) while in others (e.g. in Rebutia), series of transformations take place in seedling development. Rapid and quite large changes of the apex size in early stages of cactus organogenesis increase probability of ontogenetic transformations. Undoubtedly, the genes, involved in the selfmaintenance of the apex and the cell recruitment for primordium formation (for references see, e.g., Fleming 2005), play the crucial role in determining appropriate proportions of the cactus apex. Phylogenetic modifications of those genes have already been suggested to be a significant source of diverse apex morphologies in cacti, supporting adaptations to succulent conditions (Mauseth 2004). Current studies on the initial phyllotaxis in cacti suggest that the potential and the preference for a specific transformation may be under complex genetic control. It is most probably phylogenetically gained and maintained, determining developmental plasticity that is greater in some cactus lineages than in others. 


\section{ACKNOWLEDGEMENTS}

I would like to thank Mr. Jacek Kański from the Botanical Garden of University of Wrocław and Ms. Zofia Pyjek who kindly provided cactus seeds. My thanks are also due to Prof. Dr. hab. Beata Zagórska-Marek and Dr. Alicja Banasiak for helpful discussion and comments on manuscript.

\section{LITERATURE CITED}

ALONI R., ALONI E., LANGHANS M., ULLRICH C.I. 2006. Role of auxin in regulating Arabidopsis flower development. Planta 223: 315-328.

ANDERSON E.F. 2001. The cactus family. Timber Press, Portland, Oregon.

BACKEBERG C. 1961. Die Cactaceae. Die Handbuch der Kakteenkunde. B.V. Cereoideae (Boreocactinae). VEB G. Fischer Verlag, Jena.

BAILEY I.W. 1960. Comparative anatomy of the leaf-bearing Cactaceae. I. Foliar vasculature of Pereskia, Pereskiopsis and Quiabentia. J. Arnold Arbor. 41: 341-356.

BAILEY I.W. 1964. Comparative anatomy of the leaf-bearing Cactaceae. XI. The xylem of Pereskiopsis and Quiabentia. J. Arnold Arbor. 45: 140-157.

BANASIAK A.S. 2005. Anatomical and developmental consequences of the delay in protoxylem differentiation in Arabidopsis mutant pin1. Biol. Lett. 42: 137-138.

BARTHLOTT W., HUNT D.R. 1993. Cactaceae. In: The families and genera of vascular plants. Vol. 2. Kubitzki K., Rohwer J.G., Bittrich V. (eds), Springer Verlag, Berlin, pp. 161-197.

BOKE N.H. 1953. Tubercle development in Mammillaria heyderi. Am. J. Bot. 40: 239-247.

BOKE N.H. 1954. Organogenesis of the vegetative shoot in Pereskia. Am. J. Bot. 41: 619-637.

BOKE N.H. 1957. Comparative histogenesis of the areoles in $\mathrm{Ho}$ malocephala and Echinocactus. Am. J. Bot. 44: 368-384.

BOKE N.H. 1961. Structure and development of the shoot in Dolicothele. Am. J. Bot. 48: 316-321.

BRITTON N.L., ROSE J.N. 1923. The Cactaceae. Carnegie Institution of Washington, Washington.

CHURCH A.H. 1904. On the relation of phyllotaxis to mechanical laws. Williams and Norgate, London.

CRAIG R.T. 1945. The Mammillaria handbook. Abbey Gard. Press, Pasadena.

DOUADY S., COUDER Y. 1996. Phyllotaxis as a dynamical self organizing process. Part I: The spiral modes resulting from time-periodic iterations. J. Theor. Biol. 178: 255-274.

DOUADY S., COUDER Y. 1998. The phyllotactic patterns as resulting from self-organization in an iterative process. In: Symmetry in plants. Jean R.V., Barabé D. (eds), World Scientific Publishing Co. Pte. Ltd., Singapore, New Jersey, London, Hong Kong, pp. 539-570.

FLEMING A.J. 2005. Formation of primordial and phyllotaxy. Curr. Opin. Plant Biol. 8: 53-58.

FREEMAN T.P. 1970. The developmental anatomy of Opuntia basilaris. II. Apical meristem, leaves, areoles, glochids. Am. J. Bot. 57: 616-622.

GIBSON A.C. 1976. Vascular organization in shoots of Cactaceae. I. Development and morphology of primary vasculature in Pereskioideae and Opuntioideae. Am. J. Bot. 63: 414-426.

GIBSON A.C., NOBEL P.S. 1986. The cactus primer. Harvard University Press, Cambridge, Massachusetts, London, England.

GOLA E. 1997. Phyllotactic spectra in cacti: Mammillaria species and some genera from Rebutia group. Acta Soc. Bot. Pol. 66: 237-257.
HUDSON A. 2000. Development of symmetry in plants. Ann. Rev. Plant Physiol. Plant Mol. Biol. 51: 349-370.

HUNT D. 1992. CITES. Cactaceae checklist. Kew: Royal Botanic Gardens.

JÖNSSON H., HEISLER M.G., SHAPIRO B.E., MEYEROWITZ E.M., MJOLSNESS E. 2006. An auxin-driven polarized transport model for phyllotaxis. PNAS 103(5): 1633-1638.

KRAINZ H. 1956-1975. Die Kakteen: eine Gesamtdarstellung der eingefuhrten Arten nebst Anzucht- und Pflege-Anweisungen. Stuttgart: Franckh.

KUHLEMEIER C., REINHARDT D. 2001. Auxin and phyllotaxis. Trends Plant Sci. 6(5): 187-189.

LYNDON R.F. 1998. The shoot apical meristem. Its growth and development. Cambridge University Press.

MATKOWSKI A., KARWOWSKI R., ZAGÓRSKA-MAREK B. 1998. Two algorithms of determining the middle point of the shoot apex by surrounding organ primordia positions and their usage for computer measurements of divergence angles. Acta Soc. Bot. Pol. 67: 151-159.

MAUSETH J.D. 1978a. An investigation of the morphogenetic mechanisms which control the development of zonation in seedling shoot apical meristem. Am. J. Bot. 65: 158-167.

MAUSETH J.D. 1978b. An investigation of the phylogenetic and ontogenetic variability of shoot apical meristems in the Cactaceae. Am. J. Bot., 65: 326-333.

MAUSETH J.D. 1980. A morphometric study of the ultrastructure of Echinocereus engelmannii (Cactaceae). I. Shoot apical meristems at germination. Am. J. Bot. 67: 173-181.

MAUSETH J.D. 2004. Giant shoot apical meristems in cacti have ordinary leaf primordia but altered phyllotaxy and shoot diameter. Ann. Bot. 94: 145-153.

MAUSETH J.D., NIKLAS K.J. 1979. Constancy of relative volumes of zones in shoot apical meristems in Cactaceae: implications concerning meristem size, shape, and metabolism. Am. J. Bot. 66: 933-939.

RAUH W. 1979. Kakteen an ihren Standorten. P. Parley Verlag, Berlin und Hamburg.

REINHARDT D., MANDEL T., KUHLEMEIER C. 2000. Auxin regulates the initiation and radial position of plant lateral organs. Plant Cell 12: 507-518.

REINHARDT D., PESCE E.-R., STIEGER P., MANDEL T., BALTENSPERGER K., BENNETT M., TRAAS J., FRIML J., KUHLEMEIER C. 2003. Regulation of phyllotaxis by polar auxin transport. Nature 426: 255-260.

SALGADO TERRAZAS T., MAUSETH J.D. 2002. Shoot anatomy and morphology. In: Cacti. Biology and uses. Nobel P.S. (ed.). Univ. California Press, Berkeley, Los Angeles, London, pp. 23-40.

SCHWABE W.W. 1984. Phyllotaxis. In: Positional controls in plant development. Barlow P.W., Carr D.J. (eds), Cambridge Univ. Press, Cambridge, pp. 403-440.

STIEGER P.A., REINHARDT D., KUHLEMEIER C. 2002. The auxin influx carrier is essential for correct leaf positioning. Plant J. 32: 509-517.

WALLACE R.S., GIBSON A.C. 2002. Evolution and systematics. In: Cacti. Biology and uses. Nobel P.S. (ed.). Univ. California Press, Berkeley, Los Angeles, London, pp. 1-22.

ZAGÓRSKA-MAREK B. 1985. Phyllotactic patterns and transitions in Abies balsamea. Can. J. Bot. 63: 1844-1854.

ZAGÓRSKA-MAREK B. 1987. Phyllotaxis triangular unit; phyllotactic transitions as the consequences of the apical wedge disclinations in a crystal-like pattern of the units. Acta Soc. Bot. Pol. 56: 229-255.

ZAGÓRSKA-MAREK B. 1994. Phyllotaxic diversity in Magnolia flowers. Acta Soc. Bot. Pol. 63: 117-137. 